\title{
Peutz-Jeghers syndrome and family planning: the attitude towards prenatal diagnosis and pre-implantation genetic diagnosis
}

\author{
Margot GF van Lier ${ }^{1,6}$, Susanne E Korsse ${ }^{\star, 1,6}$, Elisabeth MH Mathus-Vliegen ${ }^{2}$, Ernst J Kuipers ${ }^{1,3}$, \\ Ans MW van den Ouweland ${ }^{4}$, Kathleen Vanheusden ${ }^{4,5}$, Monique E van Leerdam ${ }^{1}$ and Anja Wagner ${ }^{4}$
}

Peutz-Jeghers syndrome (PJS) is a hereditary disorder caused by LKB1 gene mutations, and is associated with considerable morbidity and decreased life expectancy. This study was conducted to assess the attitude of PJS patients towards family planning, prenatal diagnosis (PND) and pregnancy termination, and pre-implantation genetic diagnosis (PGD). In a crosssectional study, 61 adult PJS patients were asked to complete a questionnaire concerning genetic testing, family planning, PND and PGD. The questionnaire was completed by 52 patients ( $85 \%$ response rate, $44 \%$ males) with a median age of 44 (range 18-74) years. A total of $37(71 \%)$ respondents had undergone genetic testing. In all, 24 respondents $(46 \%, 75 \%$ males) had children. A total of $15(29 \%)$ respondents reported that their diagnosis of PJS had influenced their decisions regarding family planning, including 10 patients (19\%, 9/10 females) who did not want to have children because of their disease. Termination of pregnancy after PND in case of a foetus with PJS was considered 'acceptable' for $15 \%$ of the respondents, whereas $52 \%$ considered PGD acceptable. In conclusion, the diagnosis of PJS influences the decisions regarding family planning in one third of PJS patients, especially in women. Most patients have a negative attitude towards pregnancy termination after PND, while PGD in case of PJS is judged more acceptable. These results emphasise the importance of discussing aspects regarding family planning with PJS patients, including PND and PGD.

European Journal of Human Genetics (2012) 20, 236-239; doi:10.1038/ejhg.2011.152; published online 10 August 2011

Keywords: Peutz-Jeghers syndrome; family planning; genetic testing; pre-implantation genetic diagnosis; prenatal diagnosis

\section{INTRODUCTION}

Peutz-Jeghers syndrome (PJS) is a rare, autosomal dominant inherited disorder caused by germline mutations in the LKB1 gene. ${ }^{1,2}$ The syndrome is clinically characterised by gastrointestinal hamartomas and mucocutaneous pigmentation. ${ }^{3,4}$ Hamartomatous polyps can develop already in the first decade of life and may cause various complications, including anaemia, bleeding and acute intestinal obstruction. ${ }^{5,6}$ Furthermore, PJS is associated with an increased cancer risk in adult life. Lifetime cumulative cancer risks as high as $93 \%$ have been described. ${ }^{7,8}$ These clinical aspects of the disease affect the psychological condition and quality of life of PJS patients. They suffer from mild depression and experience a poorer mental quality of life, more limitations in daily functioning due to emotional problems and a poorer general health perception compared with the general population. ${ }^{9,10}$

Diagnostic mutation analysis is available for patients clinically suspected of PJS. Performing genetic testing might influence family planning of patients. If a pathogenic mutation is confirmed, antenatal genetic testing of offspring is available through prenatal diagnosis (PND) (ie, chorionic villus sampling and amniocentesis), which may result in the wish to terminate the pregnancy in case of an affected foetus. In addition, pre-implantation genetic diagnosis (PGD) has become available. PGD involves in vitro fertilisation (IVF). One or two cells of a 3-day old embryo created in vitro are analysed for the genetic defect, and only embryos with an unaffected genotype are selected for transfer to the uterus. ${ }^{11}$ Although PND and PGD are available for hereditary cancer syndromes in most European countries, the application of these techniques remains controversial in the social, ethical and political domain. ${ }^{12}$

Data concerning family planning of patients with PJS are lacking. Therefore, the aim of this study was to investigate the desire to have children in PJS patients, and their attitudes towards PND with the implication of pregnancy termination and towards PGD.

\section{PATIENTS AND METHODS}

\section{Patients}

A total of 61 PJS patients from 39 families from two Dutch academic hospitals were invited to complete a questionnaire on genetic testing, family planning, PND and PGD. The study was approved by the Institutional Review Boards of both participating hospitals. Patients were eligible if they were aged 18 years or

${ }^{1}$ Departments of Gastroenterology and Hepatology, Erasmus University Medical Centre, Rotterdam, The Netherlands; ${ }^{2}$ Departments of Gastroenterology and Hepatology, Academic Medical Centre, Amsterdam, The Netherlands; ${ }^{3}$ Departments of Internal Medicine, Erasmus University Medical Centre, Rotterdam, The Netherlands; ${ }^{4}$ Departments of Clinical Genetics, Erasmus University Medical Centre, Rotterdam, The Netherlands; ${ }^{5}$ Departments of Psychology, Erasmus University Medical Centre, Rotterdam, The Netherlands

*Correspondence: Dr SE Korsse, Department of Gastroenterology and Hepatology, Erasmus University Medical Centre, Room Hs 306, PO Box 2040, 3000 CA Rotterdam, The Netherlands. Tel: +31 1070 33040; Fax: +31 1070 32908; E-mail: s.korsse@erasmusmc.nl

6 These authors contributed equally to this work.

Received 10 May 2011; revised 5 July 2011; accepted 7 July 2011; published online 10 August 2011 
older and fulfilled the diagnostic criteria for PJS recommended by the World Health Organisation (see Supplementary Information online). ${ }^{13}$ The questionnaire, an information folder, a consent form and a reply paid envelope were sent to all potential participants by mail. After 6 and 12 weeks a reminder was sent to non-respondents.

\section{Measures}

The questionnaire was earlier described in detail by van Lier et al. ${ }^{10}$ Briefly, it comprised a range of demographic variables including age, gender and parenthood. As psychological determinants, concerns regarding cancer were assessed with the cancer worry scale (CWS), ${ }^{14}$ and illness perceptions were evaluated by the Illness Perception Questionnaire-Revised (IPQ-R). ${ }^{15}$ Clinical variables including history of cancer and family history of PJS were derived from medical records.

In addition, respondents were asked whether or not they had undergone genetic testing and, if they had, what the result had been. Self-reported data regarding genetic testing were confirmed by medical records where possible. Questions were posed about the current desire to have (more) children, and if the diagnosis of PJS had influenced the desire to have (more) children. Furthermore, after a short introductory text about PND and PGD, respondents were asked whether or not they considered termination of pregnancy after PND or the use of PGD acceptable; (1) in general, and (2) in case of PJS (see Supplementary Information online). Response categories were 'yes', 'no' or 'unsure.16

\section{Statistical analysis}

Data were analysed using the SPSS 17.0 statistical software for Windows (IBM, Somers, NY, USA). Descriptive statistics were used to characterise the study sample. Continuous variables were reported by means (and standard deviation) and medians (and range). Univariate analyses ( $\chi^{2}$, Fisher's exact test, independent $t$-test and Mann-Whitney $U$-test) were used to evaluate which sociodemographic, clinical and psychological variables were related to attitudes towards genetic testing, PND and PGD. A two-sided $P$-value $<0.05$ was considered statistically significant. Multivariate logistic regression analyses using backward selection with a $P$-value of 0.1 for removal of the variable was carried out to determine associations between possible confounders (sociodemographic, personal and family medical history and psychosocial determinants) and three outcome measures: genetic testing ('yes' or 'no'), termination of pregnancy after PND acceptable in case of PJS ('yes' or 'no/ unsure') and PGD acceptable in case of PJS ('yes' or 'no/unsure').

\section{RESULTS}

\section{Baseline characteristics}

The questionnaire was completed by 52 PJS patients (response rate $85 \%)$ from 34 families. Median age of respondents was 44 (18-74) years and $23(44 \%)$ were male. Baseline characteristics of the respondents and non-respondents are shown in Table 1.

There were no significant differences in age $(P=0.056)$ or cancer incidence between male and female respondents $(P=0.144)$. However, women in our cohort scored significantly higher than men on the CWS (6.41 vs 5.13, $P=0.038$ ), and on the IPQ-R subscale emotional representations (16.21 vs 12.87, $P=0.019$ ). Scores on the other six IPQ-R subscales did not differ significantly between male and female respondents.

\section{Genetic testing}

Of the 52 patients who completed the questionnaire, 37 patients had undergone genetic testing, of which 33 (89\%) were actually carrier of a pathogenic $L K B 1$ mutation. Multivariate logistic regression analysis showed female gender $(P=0.035)$ and parenthood $(P=0.016)$ as positive predictors for genetic test uptake (Supplementary Table 1).

\section{Parenthood and influence of PJS on family planning}

In all, 24 respondents (46\%; median age 50 years) had children. Female PJS patients less often had children than male patients (25 vs $75 \%, P<0.001)$.
Table 1 Baseline characteristics of respondents and non-respondents

\begin{tabular}{|c|c|c|}
\hline & $\begin{array}{c}\text { Respondents } \\
N(\%)\end{array}$ & $\begin{array}{c}\text { Non-respondents } \\
N(\%)\end{array}$ \\
\hline & 52 & 9 \\
\hline Median age (range) ${ }^{a}$ & $44(18-74)$ & $34(18-67)$ \\
\hline$\leq 45$ yrs (child-bearing age) & $29(55.8)$ & $5(55.6)$ \\
\hline$>45$ yrs & $23(44.2)$ & $4(44.4)$ \\
\hline \multicolumn{3}{|l|}{ Gender ${ }^{\mathrm{a}}$} \\
\hline Male & $23(44.2)$ & $6(66.7)$ \\
\hline Female & $29(55.8)$ & $3(33.3)$ \\
\hline \multicolumn{3}{|l|}{ Partner } \\
\hline Yes & $36(69.2)$ & Unknown \\
\hline No & $16(30.8)$ & Unknown \\
\hline \multicolumn{3}{|l|}{ Children } \\
\hline Yes & $24(46.2)$ & $5(55.6)$ \\
\hline No & $28(53.8)$ & $4(44.4)$ \\
\hline \multicolumn{3}{|l|}{ Educational level } \\
\hline Low & $29(55.8)$ & Unknown \\
\hline High & $23(44.2)$ & Unknown \\
\hline \multicolumn{3}{|l|}{ Genetic testing performed } \\
\hline Yes & $37(71.2)$ & $9(100)$ \\
\hline No & $15(28.8)$ & $0(0)$ \\
\hline \multicolumn{3}{|l|}{ Family history } \\
\hline Familial PJS & $33(63)$ & $5(55.6)$ \\
\hline Sporadic PJS/family unknown & $19(37)$ & $4(44.4)$ \\
\hline
\end{tabular}

Abbreviation: PJS, Peutz-Jeghers syndrome.

${ }^{a}$ Age $(P=0.86)$ and gender distribution $(P=0.29)$ did not differ between respondents and nonrespondents.

Of the 52 respondents, 15 (29\%, median age 44 years) reported that the diagnosis of PJS had influenced their desire to have children (ie, less or no children). Ten of these 15 respondents (19\%; median age 45 years) stated that they had decided to have no children because of PJS, including nine females and one male, the latter who had adopted a child. Cancer incidence was higher in these 10 patients (56 vs 44\%, $P=0.011$ ), and they scored higher on the CWS (8.0 vs 5.2, $P=0.039$ ) compared with the other respondents. In all, 23 of the respondents (44\%, median age 45 years) indicated that PJS had not influenced their desire to have children.

In general, the majority of respondents considered termination of pregnancy after PND and the use of PGD as 'acceptable' (62\% and $61 \%$, respectively). The attitude of respondents regarding these two techniques in relation to PJS is shown in Figure 1. Fifteen percent of patients considered pregnancy termination after PND acceptable, while $52 \%$ accepted the use of PGD in case of PJS. Results of univariate and multivariate analyses are shown in Tables 2 and 3. No significant associations were found for the attitude towards pregnancy termination after PND or towards PGD.

\section{DISCUSSION}

This is the first survey among PJS patients that evaluated their decisions regarding family planning, and their attitude towards PND with possible pregnancy termination, and towards PGD. In all, 24 respondents $(46,75 \%$ males) had children. Interestingly, there was a 
notable gender difference in our study population with respect to parenthood. Female patients less often had children than men with PJS. Furthermore, $90 \%$ of patients $(9 / 10)$ who explicitly indicated that they did not want to have children because of PJS were female. The reason for this difference is not clear. As PJS is associated with an increased risk for the development of gynaecological tumours, ${ }^{8,17}$ disabilities (eg, hysterectomy or oophorectomy) might have prevented female patients from having children. However, this was the case in only two females from our cohort (at the age of 36 and 39 years). In addition, there were no significant differences in age or cancer incidence between male and female respondents. One could postulate that psychosocial explanations for this difference exist. Women in our cohort did have more cancer worries than men, and had a higher emotional response to PJS. These findings could imply that women

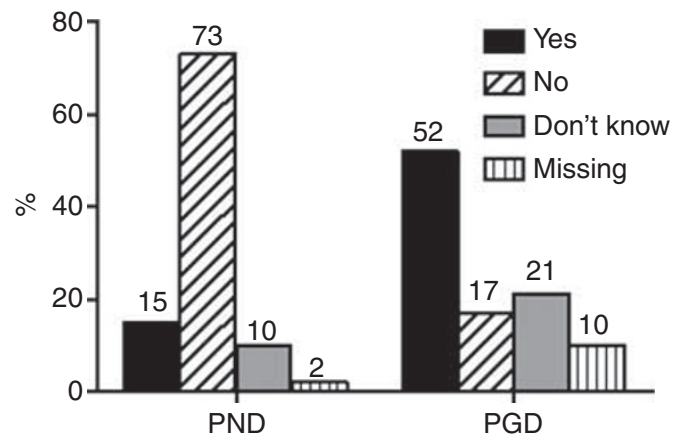

Figure 1 Attitude of PJS patients towards termination of pregnancy after PND and PGD in case of PJS. PND: acceptance of termination of pregnancy after PND in case of PJS. PGD: acceptance of the use of PGD in case of PJS. are more emotionally affected by their disease, which can render to a higher sense of responsibility towards their offspring. ${ }^{18}$

All respondents, irrespective of parenthood, were asked about their attitude towards termination of pregnancy after PND. More patients accepted the use of PGD in case of PJS than pregnancy termination after PND, suggesting a preference for PGD. This preference has been observed before in couples with different genetic disorders, including cancer susceptibility syndromes as hereditary breast and ovarian cancer and familial adenomatous polyposis syndrome. ${ }^{19-23}$ In a recent study among couples with a broad spectrum of genetic disorders, $74 \%$ of couples preferred PGD over PND for diagnostic testing in a future pregnancy. ${ }^{24}$ The preference for PGD can partly be explained by the fact that PGD offers patients the possibility to have an unaffected genetically related child while termination of a pregnancy can be avoided. Furthermore, early reassurance is seen as an important advantage. ${ }^{19}$ Though, many individuals with a hereditary condition for which PGD has been permitted, are unfamiliar with the technique or even unaware of its existence. ${ }^{24}$ In practise, PGD is physically and psychologically burdensome. ${ }^{25}$ Our questionnaire did not explore the knowledge of respondents about PND and PGD. Although both techniques were shortly described, the information might have been too limited. Furthermore, positive attitudes towards PND and PGD do not necessarily translate into actual use. ${ }^{26}$

This study is hampered by some limitations. First of all, the crosssectional study design makes evaluation of causal interactions impossible. Instead, we can only demonstrate statistical associations between determinants and the attitude towards genetic testing and reproductive decision-making. Second, only affected individuals were asked to fill in the questionnaire, not their partners, yet it is likely that partners of PJS patients have an important role in the reproductive decision making and family planning. Third, the actual use of PND and

Table 2 Determinants of the attitude towards termination of pregnancy in case of a foetus with PJS ( $=51$ )

\begin{tabular}{lll}
\hline & \multicolumn{1}{c}{$\begin{array}{c}\text { Univariate analysis } \\
\text { OR }(95 \% \mathrm{Cl})\end{array}$} & $P$-value $(95 \% \mathrm{Cl})$ \\
\hline Gender; male/female & $2.609(0.472 ; 14.406)$ & 0.271 \\
Age & $0.936(0.877 ; 0.998)$ & 0.042 \\
Aware of mutation status; yes/no ${ }^{\mathrm{a}}$ & $0.680(0.149 ; 3.099)$ & 0.618 \\
Children; yes/no & $0.124(0.014 ; 1.098)$ & 0.061 \\
PJS familial; yes/no & $0.655(0.133 ; 3.218)$ & 0.602 \\
Malignancy; yes/no & $0.625(0.067 ; 5.822)$ & 0.680 \\
CWS score & $1.165(0.881 ; 1.540)$ & 0.283 \\
\hline
\end{tabular}

Abbreviations: 95\% CI, 95\% confidence interval; CWS, cancer worry scale; OR, odds ratio; PJS, Peutz-Jeghers syndrome.

aln all, 29 respondents were aware of their mutation status; 27 LKB1 mutation positive and 2 LKB1 mutation negative.

Table 3 Determinants of the attitude towards pre-implantation genetic diagnosis in case of PJS ( $N=47$ )

\begin{tabular}{lcc}
\hline & \multicolumn{1}{c}{$\begin{array}{c}\text { Univariate analysis } \\
\text { OR }(95 \% \mathrm{Cl})\end{array}$} & $\begin{array}{c}\text { Multivariate logistic regression analysis } \\
\text { O-value }(95 \% \mathrm{Cl})\end{array}$ \\
\hline Gender; male/female & $1.455(0.454 ; 4.664)$ & 0.529 \\
Age & $1.021(0.978 ; 1.067)$ & 0.341 \\
Aware of mutation status; yes/no & $1.700(0.525 ; 5.500)$ & 0.376 \\
Children; yes/no & $1.135(0.356 ; 3.621)$ & 0.831 \\
PJS familial; yes/no & $0.343(0.078 ; 1.500)$ & 0.155 \\
Malignancy; yes/no & $0.375(0.078 ; 1.803)$ & 0.221 \\
CWS score & $1.187(0.884 ; 1.593)$ & 0.254
\end{tabular}

Abbreviations: 95\% Cl, 95\% confidence interval; CWS, cancer worry scale; OR, odds ratio; PJS, Peutz-Jeghers syndrome.

aln all, 29 respondents were aware of their mutation status; 27 LKB1 mutation positive and 2 LKB1 mutation negative. 
subsequent pregnancy termination and PGD amongst PJS patients is not known, and questions regarding religion were not included in our questionnaire, while religion can be of influence on the attitude towards both PND as well as PGD. Finally, in spite of the response rate of over $85 \%$, our conclusions are drawn from a small sample size. However, as PJS is a rare disorder it is difficult to assess a larger group. We managed to approach nearly all known Dutch PJS patients, thereby creating a heterogeneous cohort of patients enrolled in similar surveillance programs and with similar access to medical care. To our knowledge this is the first report concerning reproductive decision-making and the attitude towards antenatal diagnostics amongst PJS patients.

In conclusion, this study demonstrates that the diagnosis of PJS influences decisions regarding family planning in approximately one third of PJS patients, especially in women. The majority of patients undergo genetic testing, and many PJS patients have a positive attitude towards PGD as an option to prevent transmission of PJS to their offspring. In contrast, the attitude of respondents was predominantly negative towards pregnancy termination after PND in case of a foetus affected with the syndrome. Our results emphasise not only the importance of accurate genetic counselling for these patients; it also indicates that medical specialists dealing with patients suffering from hereditary cancer syndromes, including PJS, should discuss aspects regarding family planning, such as PND and PGD.

\section{CONFLICT OF INTEREST}

The authors declare no conflict of interest.

\section{ACKNOWLEDGEMENTS}

We would like to thank all participating PJS patients.

1 Hemminki A, Markie D, Tomlinson I et al: A serine/threonine kinase gene defective in Peutz-Jeghers syndrome. Nature 1998; 391: 184-187.

2 Jenne DE, Reimann $\mathrm{H}$, Nezu J et al: Peutz-Jeghers syndrome is caused by mutations in a novel serine threonine kinase. Nat Genet 1998; 18: 38-43.

3 Peutz JLA: Over een zeer merkwaardige, gecombineerde familiaire polyposis van de slijmliezen van den tractus intestinalis met die van de neuskeelholte en gepaard met eigenaardige pigmentaties van huid en slijmvliezen. Ned Maandschr v Geneesk 1921; 10: $134-146$.
4 McGarrity TJ, Amos C: Peutz-Jeghers syndrome: clinicopathology and molecular alterations. Cell Mol Life Sci 2006; 63: 2135-2144.

5 Utsunomiya J, Gocho H, Miyanaga T, Hamaguchi E, Kashimure A: Peutz-Jeghers syndrome: its natural course and management. Johns Hopkins Med J 1975; 136: 71-82.

6 Hearle N, Schumacher V, Menko FH et al: STK11 status and intussusception risk in Peutz-Jeghers syndrome. J Med Genet 2006; 43: e41.

7 Giardiello FM, Brensinger JD, Tersmette AC et al: Very high risk of cancer in familial Peutz-Jeghers syndrome. Gastroenterology 2000; 119: 1447-1453.

8 van Lier MG, Wagner A, Mathus-Vliegen EM, Kuipers EJ, Steyerberg EW, van Leerdam ME: High cancer risk in Peutz-Jeghers syndrome: a systematic review and surveillance recommendations. Am J Gastroenterol 2010; 105: 7.

9 Woo A, Sadana A, Mauger DT, Baker MJ, Berk T, McGarrity TJ: Psychosocial impact of Peutz-Jeghers syndrome. Fam.Cancer 2009; 8: 59-65.

10 van Lier MG, Mathus-Vliegen EM, van Leerdam ME et al: Quality of life and psychological distress in patients with Peutz-Jeghers syndrome. Clin Genet 2010; 78: 219-226.

11 Sermon K, Van Steirteghem A, Liebaers I: Preimplantation genetic diagnosis. Lancet 2004; 363: 1633-1641.

12 Lammens $\mathrm{C}$, Bleiker $\mathrm{E}$, Aaronson $\mathrm{N}$ et al: Attitude towards pre-implantation genetic diagnosis for hereditary cancer. Fam Cancer 2009; 8: 457-464.

13 Hamilton SR, Aaltonen LA: World Health Organization Classification of Tumours. Pathology and Genetics. Tumours of the Digestive System. IARC Press: Lyon, 2001.

14 Lerman C, Trock B, Rimer BK, Jepson C, Brody D, Boyce A: Psychological side effects of breast cancer screening. Health Psychol 1991; 10: 259-267.

15 Moss-Morris R, Weinman J, Petrie KJ, Horne R, Cameron LD, Buick D: The revised illness perception questionnaire (IPQ-R). Psychol Health 2002; 17: 1-16.

16 Douma KF, Aaronson NK, Vasen HF, Verhoef S, Gundy CM, Bleiker EM: Attitudes toward genetic testing in childhood and reproductive decision-making for familial adenomatous polyposis. Eur J Hum Genet 2010; 18: 186-193.

17 Hearle N, Schumacher V, Menko FH et al: Frequency and spectrum of cancers in the Peutz-Jeghers syndrome. Clin Cancer Res 2006; 12: 3209-3215.

18 d'Agincourt-Canning L, Baird P: Genetic testing for hereditary cancers: the impact of gender on interest, uptake and ethical considerations. Crit Rev Oncol Hematol 2006; 58: 114-123.

19 Snowdon C, Green JM: Preimplantation diagnosis and other reproductive options: attitudes of male and female carriers of recessive disorders. Hum Reprod 1997; 12 : 341-350.

20 Chamayou S, Guglielmino A, Giambona A et al: Attitude of potential users in Sicily towards preimplantation genetic diagnosis for beta-thalassaemia and aneuploidies. Hum Reprod 1998; 13: 1936-1944.

21 Lavery SA, Aurell R, Turner C et al: Preimplantation genetic diagnosis: patients' experiences and attitudes. Hum Reprod 2002; 17: 2464-2467.

22 Kastrinos F, Stoffel EM, Balmana J, Syngal S: Attitudes toward prenatal genetic testing in patients with familial adenomatous polyposis. Am J Gastroenterol 2007; 102: 1284-1290.

23 Menon U, Harper J, Sharma A et al: Views of BRCA gene mutation carriers on preimplantation genetic diagnosis as a reproductive option for hereditary breast and ovarian cancer. Hum Reprod 2007; 22: 1573-1577.

24 Musters AM, Twisk M, Leschot NJ et al: Perspectives of couples with high risk of transmitting genetic disorders. Fertil Steril 2010; 94: 1239-1243.

25 Van Voorhis BJ: Clinical practice. In vitro fertilization. N Engl J Med 2007; 356: 379-386.

26 de Die-Smulders CE, Land JA, Dreesen JC, Coonen E, Evers JL, Geraedts JP: Results from 10 years of preimplantation-genetic diagnostics in The Netherlands. Ned Tijdschr Geneeskd 2004; 148: 2491-2496.

Supplementary Information accompanies the paper on European Journal of Human Genetics website (http://www.nature.com/ejhg) 